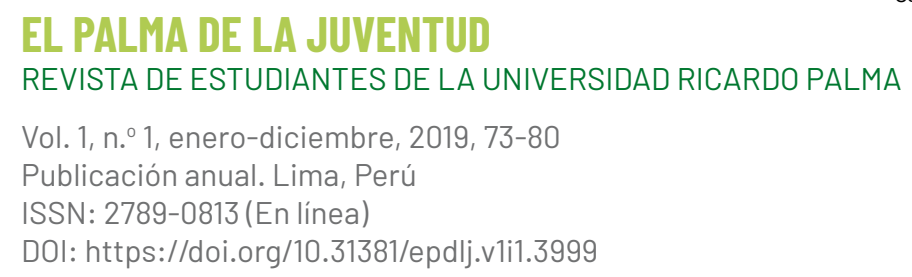

\title{
LA FIGURA DEL MÉDICO Y DE LOS HOSPITALES EN LAS TRADICIONES PERUANAS DE RICARDO PALMA'
}

\section{The figure of the doctor and hospitals in the Tradiciones peruanas by Ricardo Palma}

\section{EduARDO MEDINA HUIZA}

Facultad de Medicina Humana, Universidad Ricardo Palma

Lima, Perú

Contacto: 201920257@urp.edu.pe

\section{RESUMEN}

Este artículo analizará las tradiciones «Los barbones» $\mathrm{y}$ «Los polvos de la condesa». Se propone que en estos textos Ricardo Palma trata sobre la figura del médico y de los hospitales durante el virreinato.

Palabras clave: Tradiciones peruanas; médico; hospitales; virreinato.

1 Este artículo se elaboró como parte del curso Taller de Comunicación Oral y Escrita I, asignatura dictada por la profesora Vilma Vera Collazos Alarcón en el semestre 2019-II. 


\section{ABSTRACT}

This article will analyze the traditions «Los Barbones» and «Los polvos de la condesa». In these texts, it is proposed that Ricardo Palma discusses the figure of the doctor and the hospitals during the viceroyalty.

Key words: Tradiciones peruanas; doctor; hospitals; viceroyalty.

Recibido: 08/11/2019 Aceptado: 08/12/2019

El médico solo es ayudante de la naturaleza.

La medicina humana en el mundo es de suma importancia, ya que las sociedades se pueden medir de acuerdo con su longevidad y su calidad de vida. La medicina ha ido evolucionando a lo largo de la historia, pues desde el inicio de la humanidad se encuentran algunos vestigios de tratamientos empíricos contra diversos males que sufrió el hombre primitivo. Se utilizaron minerales, plantas, partes de animales y cualquier cosa que los chamanes de turno consideraran curativa.

En el Perú la medicina evolucionó desde los antiguos curanderos en la época inca, que utilizaban diversos métodos para la curación tales como el preparado de hierbas, la medicina espiritista y la conexión con los dioses. Con la llegada de los españoles, la medicina se presentó de una manera más desarrollada gracias a las nuevas técnicas que trajeron los médicos europeos. Sin embargo, el conocimiento aún era empírico y rudimentario.

Estos conocimientos por lo general solo se utilizaban para calmar padecimientos que no ocasionaban la muerte en su mayoría. Durante este periodo la salud no fue un derecho del pueblo y básicamente era proporcionado por la iglesia o profesionales particulares. Posiblemente el ejemplo más característico es San Martín de Porres, quien ejercía de barbero y médico empírico antes de consagrarse hermano. 
Ricardo Palma en su tradición «Los polvos de la condesa» menciona la utilización de la infusión de la quina para tratar la terciaria que la condesa doña Francisca Henríquez de Ribera había adquirido al desembarcar en Paita. Y en «Los barbones» nos cuenta cómo la orden monástica y religiosa de los betlemitas desempeñó un papel importante en la fundación de hospitales como El Refugio o El Carmen, además, señala cómo ellos daban servicio hospitalario.

Estas tradiciones nos dan una visión acerca de la figura de los médicos y de los hospitales durante la época virreinal de los años 1600, en donde el acceso a la medicina no era brindado por el virreinato peruano, y de cuánto contraste existe con la república peruana de nuestro tiempo. Luego de esta breve introducción, pasaré a analizar ambas tradiciones.

En la tradición «Los Barbones» se describe la rivalidad que existía entre las órdenes religiosas durante el virreinato: «Al principio, los bethlemitas pretendieron denominarse Compañía, y no solo ser institución hospitalaria, sino también docente; pero los jesuitas los combatieron enérgicamente, y dieron en tierra con el propósito» (Palma, 2015, p. 105).

Como puede observarse, las órdenes religiosas, al igual que en nuestros días, ejercen diversas funciones en la sociedad. Pero enfocándonos en el tema, podemos apreciar que muchas órdenes de la época virreinal prestaban servicios en docencia y servicio hospitalario, además de sus labores religiosas. Los monjes tenían la obligación del trabajo que les imponía la regla ora et labora (reza y trabaja), que era trabajo físico, pero la parte más fuerte era realizada por los hermanos legos.

La consideración del trabajo intelectual era equivalente a la del físico, y laboratorium o lugar de trabajo podía ser perfectamente el scriptorium donde se copiaban a mano los textos disponibles en las 
bibliotecas monásticas, que por muy reducidas que fueran eran los únicos lugares de transmisión del saber clásico durante la Alta Edad Media (Schwaiger, 1998, pp. 368-369).

Más adelante, Palma (2015) nos describe al público al cual se le brindaba los servicios:

Según sus primitivos Estatutos, poco evangélicos en mi concepto, debían medicinar en sus hospitales únicamente a cristianos. Para con los enfermos de religión distinta no les era obligatoria la caridad. Pero el Papa Inocencio XI, por bula de 26 de marzo de 1667, reformó los Estatutos, ordenándoles no excluir de sus cuidados a los infieles y privándolos de funciones sacerdotales por no ser los ejercicios manuales y humildes decorosos para los ministros del altar. También dispuso el Padre Santo que a los hermanos aspirantes se les enseñase algo de botánica y medicina (p. 106).

De este fragmento podemos entender que por lo general las órdenes religiosas brindaban caridad a los desahuciados, pero estos eran en su mayoría cristianos. Los indios no católicos, los judíos, protestantes u otra minoría no eran una obligación para ellos.

El papa Inocencio fue conocido por sus reformas en el Vaticano debido a que se estaba viviendo un déficit económico. Corrigió los abusos administrativos y elevó el nivel moral de los laicos (The Encyclopedia Press, 1913). Posiblemente esto nos explique por qué ya no se discriminaba a los infieles en la atención y al mismo tiempo se exigía que los religiosos tuvieran conocimientos en botánica y medicina para poder brindar mejores servicios a los ciudadanos.

Más adelante, Palma (2015) nos comenta sobre su fundador:

Sobre Pedro Bethancourt, más generalmente conocido por el venerable Pedro de San José, hemos leído crónicas que enaltecen su santidad y virtudes. [...] Y sería interminable nuestro escrito si 
fuéramos a relatar los infinitos milagros practicados o que se atribuyen al venerable Bethancourt (pp. 106-107).

El texto da a entender la alta estima que el pueblo sentía por Pedro Bethancourt, más conocido como el venerable padre Pedro de San José. Es importante recalcar que el padre llegó al principio a La Habana y luego se trasladó a Guatemala, donde vistió el hábito de la Orden Tercera y dio principio a la fundación de un hospital de convalecientes.

Pero el personaje más influyente de la orden no fue su fundador, sino su sucesor: «Resultó del percance la conversión del ex capitán general de Costa Rica y flamante marqués de Talamanca, quien sin pérdida de tiempo vistió el hábito de hospitalario, tomando el nombre de fray Rodrigo de la Cruz» (Palma, 2015, p. 107). Fray Rodrigo de la Cruz fue quien le dio a esta orden religiosa los cimientos para ser una verdadera organización. Fue él quien redactó los estatutos betlemitas; luego procedió con la fundación del primer hospital, el Carmen, destinado a curar la convalecencia de las enfermas del Santa Ana; también hizo fundaciones similares en Chachapoyas, Cajamarca, Piura, Trujillo y Huanta; expulsó a los hermanos revoltosos de la orden por desacato a los estatutos, y consiguió una bula reformadora del papa Inocencio XI. Al retornar, fue nombrado prefecto general y murió en México por consecuencia de un ataque de gota el 23 de septiembre de 1716.

La labor social de la orden betlemita fue amplia y buscaba dar ayuda a cuantas personas se pudiera:

En sus mejores tiempos, los betlemitas peruanos asistían en el hospital del Refugio o de Incurables hasta a cincuenta infelices al cargo de ocho religiosos, y en la casa grande de Barbones hubo ocasión en que cuarenta hermanos atendieron a ciento sesenta enfermos. Y en el Cuzco, donde la enfermería tuvo capacidad para admitir hasta ciento veinte tarimas, llegaron a veintiocho los conventuales (Palma, 2015, p. 111). 
Es incuestionable que los betlemitas alcanzaron una alta importancia y popularidad debido a sus servicios a los ciudadanos, y que en el Perú de esta época se les tuvo en alta estima por su trabajo con los desamparados y enfermos.

Otro ejemplo sobre la figura del médico lo encontramos en la tradición «Los polvos de la condesa». Veamos el siguiente párrafo:

El doctor Juan de Vega, nativo de Cataluña y recién llegado al Perú, en calidad de médico de la casa del virrey, era una de las lumbreras de la ciencia que enseña a matar por medio de un récipe.

— ¿Y bien, don Juan? — le interrogó el virrey, más con la mirada que con la palabra.

- Señor, no hay esperanza. Solo un milagro puede salvar a doña Francisca.

Y don Juan se retiró con aire compungido (Palma, 2014, p. 316).

Podemos deducir de este fragmento que Palma nos da a entender que durante el virreinato los mejores médicos se encontraban en Europa, pero al mismo tiempo se menciona que su medicina no era capaz de curar todas las enfermedades, siendo incluso la paciente la condesa de Chinchón.

Continuando con esta tradición, líneas más adelante Palma (2014) nos describe a un sacerdote jesuita:

— Se salvará la condesa, excelentísimo señor — contestó una voz en puerta de la habitación.

El virrey se volvió sorprendido. Era un sacerdote, un hijo de Ignacio de Loyola, el que había pronunciado tan consoladoras palabras.

El conde de Chinchón se inclinó ante el jesuita. Este continuó:

-Quiero ver a la virreina, tenga vuecencia fe y Dios hará el resto.

El virrey condujo al sacerdote al lecho de la moribunda (p. 317). 
De este hecho se da a entender que los sacerdotes jesuitas conocían la cura para la terciaria, y leyendo más nos enteramos de dónde adquieren dicho conocimiento:

Atacado de fiebres un indio de Loja llamado Pedro de Leyva, bebió para calmar los ardores de la sed, del agua de un remanso, en cuyas orillas crecían algunos árboles de quina. Salvado así, hizo la experiencia de dar de beber a otros enfermos del mismo mal cántaros de agua, en los que depositaba raíces de cascarilla. Con su descubrimiento vino a Lima y lo comunicó a un jesuita, el que, realizando la feliz curación de la virreina, hizo a la humanidad mayor servicio que el fraile que inventó la pólvora (Palma, 2014, p. 319).

Es así como nos enteramos de que de un hecho empírico se obtuvo un remedio que le hizo un bien a la humanidad. Es necesario comentar que los jesuitas guardaron el secreto y que negociaron con la cura, entendiendo claramente que las órdenes religiosas se manejaban por números de fieles y servicios a la comunidad. Algo muy parecido con la medicina de nuestro tiempo, donde los médicos si bien no nos ocultan la medicina, no siempre nos brindan el nombre o la alternativa genérica del medicamento, acción que favorece a la industria farmacéutica. En conclusión, se puede imaginar al médico de la época virreinal descrito por Ricardo Palma en sus tradiciones como un profesional en medicina o como un sacerdote con estudios de medicina y que básicamente curaba de manera empírica sin saber realmente cuál era la causa de la enfermedad.

Estas tradiciones nos brindan un contraste interesante al comparar a los médicos de la época virreinal con la sociedad actual, debido a que hoy en día ya no es la Iglesia la que brinda los servicios hospitalarios sino el Estado, y que a su vez los refugios, hospitales, centros de atención, asilos y demás eran propiedad de las órdenes religiosas. 
También apreciamos que los médicos de las órdenes religiosas tenían una buena educación y reputación en la sociedad. Ello debido a sus dones humanos, pues eran capaces de simpatizar con la gente, $y$ por eso algunos adinerados de la época donaban dinero para causas sociales, específicamente para los hospitales.

Estos hospitales eran lujosos para la época, pero al mismo tiempo eran pequeños si los comparamos con los hospitales de nuestro tiempo debido básicamente a la reducida población en el virreinato.

Para finalizar, es necesario recalcar la figura del papa Inocencio XI, quien dispuso que estos servicios médicos, en un principio destinados solo a los cristianos, fueran para todos; y también ordenó que los sacerdotes tuvieran estudios en medicina y botánica, es decir, el papa mencionado fue un actor importante en la historia de la salud pública.

\section{REFERENCIAS}

No Gracias (2016, 28 de febrero). La industria farmacéutica está matando la medicina, pero podemos evitarlo. http://www.nogracias. org/2016/02/28/la-industria-farmaceutica-esta-matando-lamedicina-pero-podemos-evitarlo/

Palma, R. (2014). Los polvos de la condesa. En Tradiciones peruanas. Primera y segunda series (M. Á. Rodríguez Rea, ed.; pp. 315-320). Universidad Ricardo Palma, Editorial Universitaria.

Palma, R. (2015). Los barbones. En Tradiciones peruanas. Séptima y octava series (M. Á. Rodríguez Rea, ed.; pp. 105-116). Universidad Ricardo Palma, Editorial Universitaria.

Schwaiger, G. (1998). La vida religiosa de la A a la Z. San Pablo.

The Encyclopedia Press (1913). The Catholic Encyclopedia. Robert Appleton Company. 